\title{
WOMEN AND CHILD ABUSE IN SOUTH AFRICA: LESSONS FROM PRACTICE
}

\section{Sheri Hanson}

\section{INTRODUCTION}

A South African exploratory research study (Hanson, 2008) focusing on the phenomenon of the co-occurrence of woman and child abuse in the same family system confirmed international findings (Beeman \& Edleson, 2000; Park \& Kahn, 2000) that this phenomenon, although poorly recognised, does exist. Although international research findings point to an increase in the co-occurrence of woman and child abuse, it remains largely misunderstood in South Africa, with organisations and social workers addressing either woman abuse or child abuse, but not the two together (Hanson, 2008; Hanson \& Patel, 2009; Hanson \& Patel, 2010).

The study revealed that organisational policies and mandates as well as the theoretical frameworks of the social workers shape the way in which the co-occurrence of woman and child abuse is understood and limits intervention directed at both the mother and the child (Hanson, 2008; Hanson \& Patel, 2010).

Theoretical frameworks influencing social workers' practice were found to differ greatly between women's advocacy workers (who mostly adopt a feminist framework) and child welfare workers (who mostly follow a child-centred approach). The study found that these two different theoretical frameworks coupled with organisational mandates result in different approaches to risk assessment, safety and intervention, with a focus on either the safety of the woman or the safety of the child (Hanson, 2008). Research in both the United Kingdom and in the United States of America has highlighted the serious implications that the phenomenon of woman and child abuse occurring in the same family system has for practice (Chamberlain, 2001; Mullender, 2001). The aforementioned study on the co-occurrence of woman and child abuse in South Africa (Hanson, 2008), confirmed international findings that, whilst child welfare social workers and abused women's advocates both share an interest in stopping the violence and abuse, their perspectives and approaches are frequently in conflict (Beeman \& Edleson, 2000; Hanson, 2008; Magen, Conroy \& Del Tufo, 2000; Whitney \& Davis, 1999).

The study (Hanson, 2008) found the co-occurrence of woman and child abuse to be complex and multifaceted, and that this cannot be addressed adequately using only one level of intervention or one theoretical framework. In addition, a specialist approach to services in the South African context, where resources are minimal, does not appear to be addressing this phenomenon holistically and there is a need for a more contextually appropriate response (Hanson, 2008).

The article begins by examining the link between woman and child abuse and provides an outline of the generalist practice framework, which is used as the conceptual framework of the article. The generalist practice model as described by Kirst-Ashman and Hull (2002) has been used to portray the cases in a sequential manner. Case studies have then been used to illustrate the way in which organisations view the co-occurrence of woman and child abuse, the consequences resulting from their approach and the way in which intervention in such cases takes place. Lessons from practice have been highlighted and a more holistic assessment process is proposed to address the bifurcation in practice. The article proposes that in order to adequately protect both women and children, it is vital that assessment and intervention 
strategies be employed in order to overcome the split that exists in South Africa between organisations that address the needs of women and those that address the needs of children.

\section{THE LINK BETWEEN WOMAN AND CHILD ABUSE IN SOUTH AFRICA}

Whilst there are no statistics in South Africa on the co-occurrence of woman abuse and child abuse within the same family systems, what is known is that child abuse and woman abuse are serious and growing phenomena (Kim \& Motsei, 2002; South African Police Services, 2008). Current legislation enacted after the institution of democracy in South Africa such as the Domestic Violence Act, 116 of 1998, and the Children's Act, 38 of 2005, advocates for an empowerment approach to child and family welfare, the promotion of gender empowerment and a more generic social work practice, so that more than one social problem can be assessed and addressed within the same family system by a single social welfare service. However, it appears that welfare organisations and women's advocacy organisations involved in service delivery to women and children do not assess for both forms of abuse simultaneously (Hanson \& Patel, 2010; Hanson, 2008). The aforementioned legislation provides a broad mandate for practice, but there appears to be a gap between policy and legislation, on the one hand, and what takes place in practice, on the other (Jacobs \& Jewkes, 2002). Furthermore, there is an inconsistency between policy, practice and service delivery that is orientated only towards women and those that are directed specifically at children. Consequently, the needs of both parties are not addressed in an integrated way (Hanson, 2008).

Research from both the United States of America and the United Kingdom has highlighted the overlap between woman abuse and child maltreatment in the same family system, with an emphasis on the overlap being greater in the more serious cases of abuse (Fleck-Henderson, 2000; Mullender, 2001). A South African study at the Red Cross Children's Hospital also pointed to the co-occurrence of woman and child abuse in the same family system, where $47 \%$ of children presenting with non-accidental head injuries over a three-year period (1998-2001) were the unintended victims of domestic violence (Fieggen, Wiemann, Van As \& Swingler, 2004). This indicates a high prevalence of the co-occurrence of woman and child abuse, which is not necessarily screened for and therefore not recognised. Poor screening and assessment methods may then result in inappropriate intervention strategies being administered.

There are a number of ways in which woman abuse and child abuse may co-occur. The majority of abused women have children, which means that when a woman is abused in a relationship, there is a high likelihood that children will be exposed to, or hurt by, the abuse in some way. Often children get hurt when they become involved in domestic violence in order to protect their mothers, or merely by being accidentally hurt in "the line of fire". A batterer may also use the children to terrorise or spy on their mother. The abuser's intent to hurt his partner may result in abusing the child emotionally and/or physically (Beeman \& Edleson, 2000; Mills, Friend, Conroy, Fleck-Henderson, Krug, Magen, Thomas \& Trudeau, 2000). Children exposed to abuse are likely to be affected themselves by fear, anxiety and disruption to their lives, even when they are not directly abused (Mullender, Hague, Imam, Kelly, Malos \& Regann, 2002; Mullender, 2001; Park \& Kahn, 2000).

Women's advocates and child protection workers approach safety, risk assessment and intervention from very different conceptual frameworks. Women's advocates focus on the needs of the woman and helping her to be safe either by choosing to stay or leave the abusive relationship, whilst child protection workers focus on the safety of the child first, often leaving the mother in a dangerous situation, having to mediate between social workers in the welfare 
sector and an abusive partner (Beeman \& Edleson, 2000; Whitney \& Davis, 1999). This dichotomy has a number of implications for risk assessment and intervention. Failing to assess for woman abuse in child abuse cases results in various responses that could further complicate the situation and impact negatively on the family system. For example, child welfare workers tend to label mothers as neglectful, and may not provide her with the necessary resources to keep herself and her children safe (Fleck-Henderson, 2000). Not incorporating the feminist approach along with the child welfare approach may also result in child welfare social workers placing all the responsibility for safety and parenting on the mother, whilst absolving the perpetrator of all responsibility (Chamberlain, 2001). Failing to provide abused women in child welfare cases with the necessary resources and intervention to keep herself and her children safe can also instigate the unnecessary and traumatic removal of children from both parents (Edleson, 2001).

\section{Generalist practice as a means of overcoming the split}

The generalist practice framework was chosen as a practice framework to illustrate the themes in the case studies as it facilitates the integration of aspects of feminist theory (which is widely used by women's advocacy agencies) as well as aspects of child-centred theory (widely used by child welfare workers). It also allows for an integrated response to woman and child abuse and moves away from dealing exclusively with one client group to the exclusion of all others. The generalist approach in social work emerged in the 1970s and was a critique of the medical model which focused on pathology and treatment only. The development of generalist practice emerged during this period, when new services were evolving and new groups of clients were being served who did not fit neatly into the traditional casework, group work or community work models (Briedland, Costin \& Atherton, 1975). The approach is appropriate in the South African context as it forms one of the features identified by Patel (2005) of the developmental model of welfare services. One of the aims of developmental social welfare is to provide services in an integrated way based on the generalist approach to social work practice. Social development incorporates the use of generalist practice so as to address problem situations on multiple levels of intervention, using an eclectic knowledge base to empower individuals, families, groups and communities and organisations (Patel, 2005).

Generalist social work practice involves the assessment and treatment of a range of social problems, thus requiring competency in a broad spectrum of areas instead of being limited to a specific set of skills and competencies to address a particular problem situation only (Johnson, 1992; Kirst-Ashman \& Hull, 2002; Patel, 2005). Generalist practice is an attempt to develop the social worker's knowledge base so that she/he can select the most positive intervention strategy at the most appropriate level (Mattaini, Lowery \& Meyer, 2002). Research in both the fields of woman abuse and child abuse has shown that these social phenomena occur alongside a number of other social problems such as mental illness, drug and alcohol abuse, personality disorders, poverty, unemployment and poor social support structures, to name a few (Dangor, 1999; Eisikovits \& Buchbinder, 2000; Owens-Manley, 1999). Addressing domestic violence and child abuse would therefore necessitate a generalist approach in order to address these phenomena holistically.

Generalist practice is defined by Kirst-Ashman and Hull (2002:7) as "the application of an eclectic knowledge base, professional values, and a wide range of skills to target systems of any size, for change within the context of four primary processes". A generalist perspective is seen by Jackson (2001:8) as a means to assist social workers in "maintaining a focus on the 
dynamic interplay of the many biological and social systems that affect client behaviour and social functioning"

The generalist approach to social service delivery includes multiple levels of intervention and incorporates work with individuals, families, groups, communities and institutions. Generalist service delivery is based on the planned change model as described by Kirst-Ashman and Hull (2002). This model is designed to work with client systems of different sizes as well as a diversity of client populations and situations in an integrated manner. The central philosophical concepts underpinning the approach draw from both private issues and social justice concerns (Patel, 2005). Two core principles of the generalist approach, essential to work with women and children, are those of empowerment and gender-sensitive practice. Empowerment refers to "the process by which individuals and groups gain power, access resources and control over their own lives" (Robbins, Chatterjee \& Canda, 1998:91). This process enables people to realise their highest personal and collective ambitions and goals. Empowerment is also concerned with addressing the social and economic inequalities intrinsic to the way in which society is structured and organised, which leads to social and economic exclusion and marginalisation (Patel, 2005). Gender-sensitive practice requires the social worker to be sensitive to, and knowledgeable about, gender and the particular challenges and social issues that women may have to face (Kirst-Ashman \& Hull, 2002). The generalist practice model described by Kirst-Ashman and Hull (2002) is used to guide intervention in addressing any social problem and is briefly outlined below.

\section{The generalist practice model}

The generalist practice model is an intervention model designed to provide step-by-step directions on how to undertake the planned change process which aims at addressing problems. The model has three features. First, the model assumes that social workers have an eclectic knowledge base, a wide range of skills to target any size client system, and a professional value base. Second, there is a seven-step planned change process which emphasizes client strengths. The seven steps of the process are: engagement, assessment, planning, implementation, evaluation, termination and follow-up. The family is engaged and a professional relationship is established with the family system. An assessment is conducted in order to ascertain the needs of the family from a micro-, mezzo- and macro-level perspective. A plan for change is formulated, after which the plan is implemented. Once the implementation has taken place, evaluation of the intervention takes place. Should the intervention be evaluated as successful, the service is terminated and a follow up will occur at a later stage. Should the intervention be evaluated as unsuccessful, it is reassessed and followed up until intervention can be terminated. The third feature is the generalist approach, which means that any type of problem situation can be analysed and addressed from multiple levels of intervention, i.e. micro, mezzo and macro levels (Kirst-Ashman \& Hull, 2002).

For the purpose of this article the cases have been analysed according to three main themes: engagement, assessment and intervention.

\section{CASE STUDIES}

Methodological triangulation as described by De Vos (2001) was utilised to collect data in the study. This involved the use of more than one method of data collection, namely face-to-face interviews, analysis of case files, analysis of secondary sources, i.e. policy documents as well as the analysis of intake forms. Triangulation analysis was used in order to increase the 
trustworthiness of the data (De Vos, 2001). This article focuses only on the case studies and the methodology adopted for this is discussed briefly below.

Two case files, describing woman and child abuse within the same family, taken from two different organisations were analysed thematically. They addressed the following themes: contributing factors, methods of intervention, responses to intervention. Case studies were considered to be more appropriate in this instance as they provided the researcher with a more comprehensive description of the application of the interventions used by social workers. The information gleaned from the two case files provided the researcher with an insight into the practice methods that were used by social workers at the respective agencies. It also informed the researcher's proposal for new practice approaches and principles (Marlow, 2005). A schedule was devised to conduct the analysis of the case files. This method was extremely useful as it allowed the researcher to look at the difference between respondent's theoretical understanding of the phenomenon and how this is translated into practice.

One of the case studies (Case A) presented in this article was drawn from an organisation providing only child protection/welfare services, whilst the other case study (Case B) comes from an organisation providing services to both abused women and children. It is important to note, however, that whilst the second agency is mandated to work with the whole family, it also has statutory obligations with regards to child welfare. The cases will now be presented using Kirst-Ashman and Hull's (2002) generalist practice model.

\section{Engagement}

Engagement is the initial stage where the social worker begins to familiarize herself with the problem situation and starts to connect and communicate with the target system. In this study it was found that the specific target system is defined by the organisational mandate, which meant it could be the woman, child or family.

Both cases were referred to their agencies by an initial source (neighbour and school, respectively) and after a futile attempt at making contact with the families by the agency social worker, the cases were referred a second time by different sources (hospital and police, respectively). Clients affected by woman and child abuse frequently present with fear, shame and ambivalence regarding the helping process. These clients are often involuntary and are referred by other systems, for example, the school or clinic, which are concerned for their safety, or who have made judgments regarding their own ability to keep themselves and their children safe (Kirst-Ashman \& Hull, 2002).

Once the complaint had been lodged by an outside agency, the social worker had more authority to intervene, making it easier to engage with the client. It seems that clients became defensive in the initial engagement process, as social workers were perceived as a threat rather than a resource.

In both cases disclosure of child abuse by the parent did not occur in the engagement phase. It is unclear from the case files why the disclosure may not have taken place; however, research has provided a number of possible reasons why an abused mother may not be willing disclose that her children are also being abused. First, it may be feared that if the abuse of the children is discovered, the children will immediately be removed. Second, some women may themselves be the abusers of the children and may fear punishment. Third, hiding the abuse of the children may be a way of protecting the husband or partner so as not to ruin the possibility of returning to the relationship. Finally, women are ashamed. The acknowledgement of child abuse exposes their inability to keep their children safe and so they choose silence (McKay, 1994). Given that 
abused women are not likely to disclose child abuse for the above reasons, assessment processes need to account for this and assess for co-occurring child abuse in a different way.

In case A physical abuse of the child was initially reported; there was a suspicion of woman abuse based on the communication and interaction between the couple, but this was never investigated. No other forms of abuse were investigated or reported on the file. This case highlights the way in which organisations focus on a particular client group and even where there is a suspicion of another form of abuse, it is not investigated, leaving the other forms of abuse undetected and neglecting the needs of the other family members. Case B was quite different in that multiple forms of abuse presented themselves throughout the case history. The initial abuse was that of physical, sexual and emotional abuse of the mother perpetrated by the father, abuse of the elderly was reported soon after, followed by child abuse and neglect; it was also discovered through face-to-face interviews with the mother that she had been abused and removed from her parents as a child. Had the clients not disclosed the information voluntarily, it may not have emerged at all, because there is no indication that any questions were asked directly about any other forms of abuse. This finding is consistent with international studies, which showed that standardized screening for woman abuse in child protection cases increases the number of cases identified as experiencing woman abuse, which were not identified before the screening took place (Whitney \& Davis, 1999).

In both cases a number of other people and service providers were involved in the intervention; these included doctors, social workers in private practice, extended family members, neighbours and lawyers in Case A, and all members of the family as well as various other service providers such as the police, South African National Council for Alcohol Abuse (SANCA) and women's shelters in Case B. The importance of partnerships between different organisations working together to address the co-occurrence of woman and child abuse is essential, as no one system or organisation is capable of, or should be held responsible for, meeting all the complex needs of families affected by domestic violence (Whitney \& Davis, 1999). An integrated response drawing on the resources and expertise of various service providers as seen in Cases A and B is therefore vital. If the seemingly insuperable differences between women's advocacy agencies and child protection/welfare agencies are to be overcome, those involved in both issues must come together to provide an effective and comprehensive service to the client system (Fleck-Henderson, 2000).

In both cases the clients were involuntary; however, in Case B, after many referrals to the organisation, the clients began to seek help voluntarily from the organisation in times of crisis. This suggests that a positive connection was formed between the client and the organisation, and the organisation was perceived as a helping body rather than a punitive one. In Case A the clients remained involuntary and hostile, perhaps owing to the fact that their child had been removed from their custody very early in the intervention.

It is common knowledge that clients seek help from many different sources (Magen et al., 2000) and in both cases this was evident as they had prior contact with other agencies. In Case A there was contact with various medical facilities and in Case B there were numerous contacts with agencies such as Sterkfontein Hospital (mental health facility), the criminal justice system and the child welfare system. In Case B there was evidence of an intergenerational history of abuse, child removal and involvement of child welfare agencies. Prior interventions had clearly not been useful to the clients and perhaps an exploration of this could have influenced future interventions. Clients are often labelled as suffering from "learned helplessness", which perpetuates their victim status and prevents them from breaking free of the cycle of violence 
and abuse. Hampton and Washington Coner-Edwards (1993) suggest that clients remain in, and repeat the dynamics of, abuse not because of a "learned helplessness", but rather because of numerous failed attempts at breaking this cycle. In other words, clients may have received many interventions, all of which have been unsuccessful.

Prior to the presenting problem, both Cases A and B received intervention from the agencies concerned. At no point was it evident that the clients were included in the formulation of the intervention plan and it appeared that the clients eventually began to turn to the agency to "solve" or "fix" the crisis. In this case not only did the clients lack a sense of ownership over the process, but they became dependent on the organisation for assistance. If clients do not feel that they are included in and own the intervention plan themselves, their motivation to cooperate will most likely be very poor.

\section{Family composition}

Neither case had a genogram, making it difficult to understand the family composition. Based on the information on the files, the family compositions of the two cases are illustrated in genograms $\mathrm{A}$ and $\mathrm{B}$ below:

\section{GENOGRAM A}

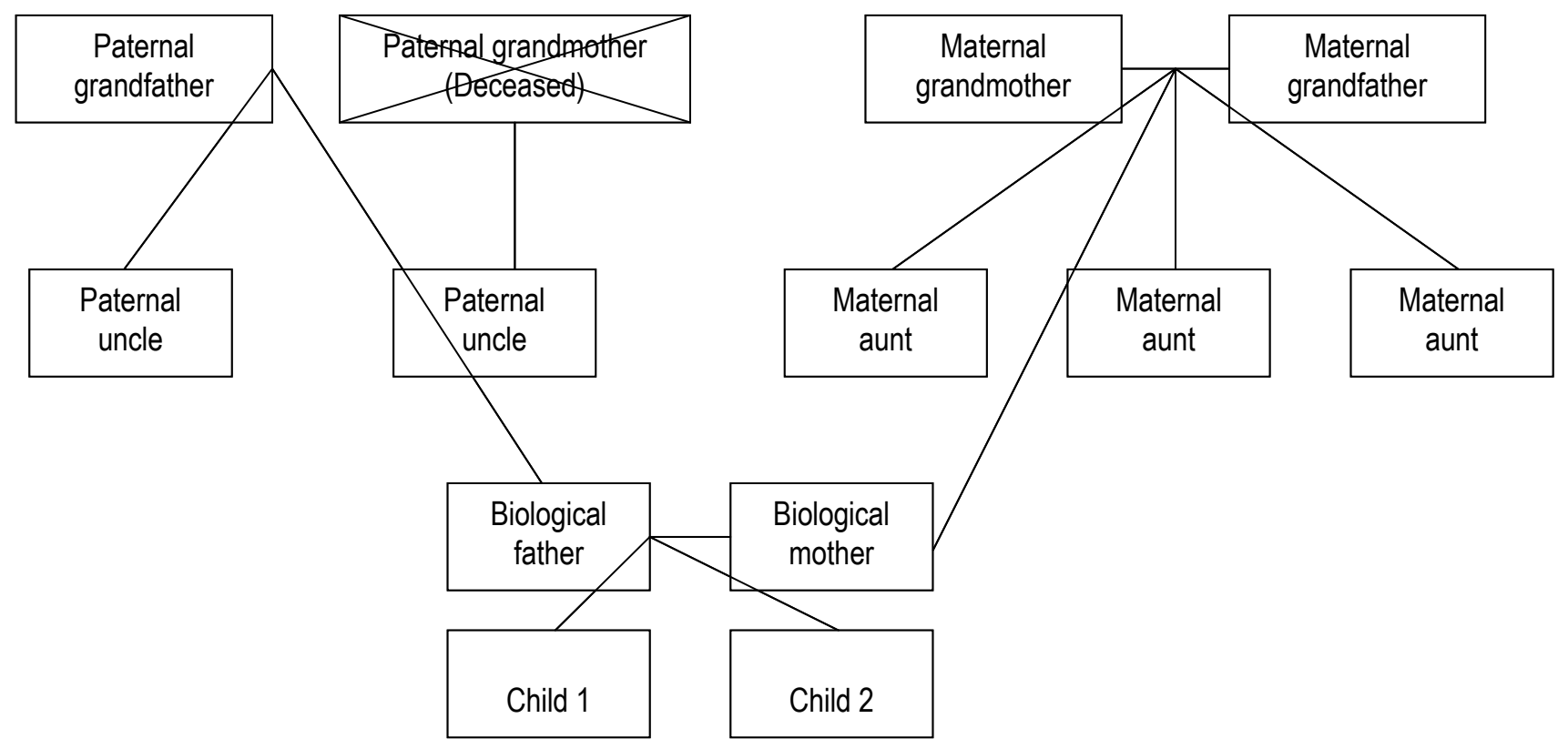




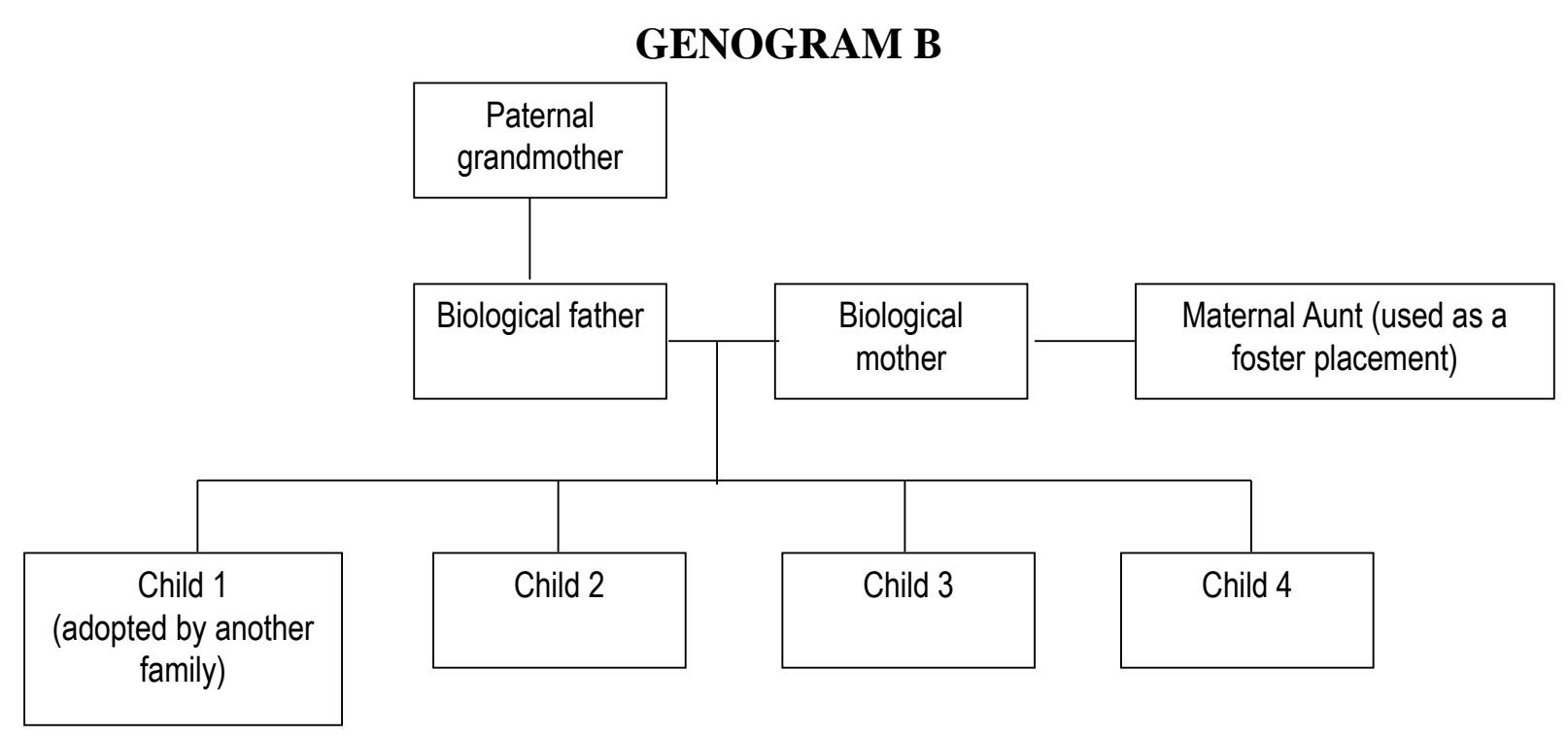

The family in Case A appeared to be completely isolated both from members of their extended families as well as from other social contacts. This is consistent with the findings from other research (Schewe, 2002) as well as the interviews conducted in this research study (Hanson, 2008 ) in that respondents identified isolation as a contributing factor to abuse. In both Cases A and $\mathrm{B}$ accommodation changed frequently and it was never clear from the files with whom accommodation was being shared.

At different points in the intervention both the biological fathers from Cases A and B were unemployed; again this is consistent with other findings from this study which indicate unemployment as a major contributor in abuse. In Case A the family was living off the biological mother's salary and was struggling to meet their financial commitments. In Case B, even when both parents were employed, they did not manage to meet the family's material needs.

\section{Assessment}

In both Case A and Case B no formal assessment was conducted by the social worker. Information was gathered via home visits, face-to-face and telephonic interviews. In Case A a formal assessment in the form of a psychological assessment was conducted on both parents by an educational psychologist and an observation was made by the occupational therapist.

The goals for Case A were easy to identify, whereas in Case B they were never clearly cited as part of a treatment plan. However, in Case A consultation with the parents is not evident as far as development of the treatment goals is concerned and a treatment plan was formulated between the social worker and her supervisor; in Case B the goals, although not always clear, appear to be formulated in conjunction with the client. Kirst-Ashmann and Hull (2002) stress the importance of involving clients in the process in order to create a sense of ownership and to enhance the client's right to self-determination. The following themes are presented in terms of assessment: family dynamics in terms of interaction, communication and boundaries; contributing factors to domestic violence and child abuse; bio-psychosocial impact on the mother and bio-psychosocial impact on the child. 


\section{Family dynamics in terms of interaction, communication and boundaries}

Common dynamics between the cases are poor parenting skills, poor relationships with members of the extended families, volatile and aggressive communication as well as use of abusive language. In addition, Case A had a dynamic of patriarchy and male domination, and Case B had poor family boundaries and broken attachments. All these characteristics are commonly noted in the literature as dynamics of abusive families (Edleson, 2001; Salzinger, Feldman \& Stockhammer, 2002).

\section{TABLE 1}

CONTRIBUTING FACTORS TO DOMESTIC VIOLENCE AND CHILD ABUSE

\begin{tabular}{|l|l|l|}
\hline \multicolumn{1}{|c|}{$\begin{array}{c}\text { Common } \\
\text { Contributing Factors }\end{array}$} & \multicolumn{1}{c|}{$\begin{array}{c}\text { Contributing Factors in Case } \\
\text { A only }\end{array}$} & $\begin{array}{c}\text { Contributing Factors in Case } \\
\text { B only }\end{array}$ \\
\hline Poor parenting skills & Patriarchy & Mental illness \\
\hline $\begin{array}{l}\text { Inability to use support } \\
\text { systems }\end{array}$ & $\begin{array}{l}\text { Head injury resulting in poor } \\
\text { impulse control }\end{array}$ & Criminal behaviour \\
\hline $\begin{array}{l}\text { Lack of resources and } \\
\text { support systems }\end{array}$ & Maternal depression & Substance abuse \\
\hline Unplanned pregnancy & Low-birth-weight baby & Anti-social behaviour \\
\hline Unemployment & $\begin{array}{l}\text { Unrealistic expectations of the } \\
\text { child }\end{array}$ & $\begin{array}{l}\text { Mother's own history of physical } \\
\text { and sexual abuse }\end{array}$ \\
\hline $\begin{array}{l}\text { Limited financial } \\
\text { resources }\end{array}$ & $\begin{array}{l}\text { Retrenchment of abuser } \\
\text { parents }\end{array}$ \\
\hline & $\begin{array}{l}\text { Low self-esteem and poor self- } \\
\text { concept }\end{array}$ & $\begin{array}{l}\text { Lack of empathy from both } \\
\text { by parents }\end{array}$ \\
\hline & Isolation of family & \multicolumn{1}{|c|}{} \\
\hline
\end{tabular}

The contributing factors in both cases as illustrated in Table 1 are consistent with those mentioned in the literature (Dominelli, 2002; Edleson, 2001). However, these contributing factors are not identified as such in the files and therefore did not form part the treatment plan.

\section{Bio-psychosocial impact on the mother}

In Case A the mother presented as depressed and suicidal. In Case B the mother also presented with symptoms of depression, and in addition presented with alcohol abuse, violent and abusive behaviour, neglect of the child and physical abuse of the child. In neither case is it clear whether these symptoms or behaviours are as a direct result of the abuse they experienced. An understanding of how the dynamics of abuse affect and influence the mother's behaviour is crucial, as this understanding may help the social worker assess whether this mother, given the right resources and support could protect herself and her children (Mills et al., 2000).

\section{Bio-psychosocial impact on the child}

In Case A there was a delay in developmental milestones of the child, specifically in the acquisition of speech, physical injuries, non-accidental head injuries, visual loss, brain seizures, irritability, boundary and attachment difficulties. In Case B there were a number of symptoms such as anti-social and criminal behaviour, bedwetting, behavioural problems at school, poor 
attachments, substance abuse, poor academic performance, risk-taking behaviour, unprotected sexual contact, truancy and running away from home. In both cases the symptoms are severe. All these symptoms are consistent with the literature on children exposed to child and women abuse (Herrera \& McClosky, 2001; Rossman, Hughes \& Rosenberg, 2000; Sappington, 2000). The concern in Case B is that the link between exposure to such family violence and the presenting behaviours is not shown and does not reflect in the intervention strategies.

\section{Intervention}

The interventions that were offered in both Case A and Case B were not always taken up by the clients. Interventions in both cases involved a multidisciplinary approach. In Case A the clients were referred for a psychological assessment, parenting counselling as well as an occupational therapy assessment. In Case B the clients were referred for substance abuse rehabilitation, referral to a shelter, while individual counselling and supportive services were also offered. In both Cases A and B statutory intervention took place with the removal of the children concerned and subsequent alternative placements. In both cases criminal investigations were opened by the South African Police Services against the parents, with direct reference to the physical abuse of the children. Intervention has been discussed in terms of micro-, mezzo- and macro-level intervention; formulation of a treatment plan; evaluation and follow up of services as well as a theoretical framework.

\section{Intervention on a micro, mezzo and macro level}

The generalist intervention model as proposed by Kirst-Ashman and Hull (2002) suggests that intervention should occur on all levels of practice. The micro level of intervention refers to social work practice with individuals, families and small informal groups. Intervention is mainly centred on the local realm of action and interaction. The mezzo level of practice refers to work with formal organisations, groups and networks, and its focal point of action may be local, provincial or national. Macro-level interventions occur more broadly. These refer to social work practice with communities, policies and legislative interventions, and intervention that may occur nationally, regionally or globally (Patel, 2005).

In both cases there are micro-level interventions in the form of counselling and face-to-face interviews. In both cases mezzo-level intervention can be seen in the form of liaison with other professionals, organisations and service providers. In Case B another mezzo-level intervention was seen in the form of assisting the mother to obtain a Peace Order against the father. There is no evidence of macro-level strategies or interventions in either of the case files.

\section{Formulation of a treatment plan}

In both cases a formal contract or treatment plan was only evident on the file once the children had been removed. In Case A the treatment plan was formulated between the social worker concerned and medical practitioners. In Case B it was difficult to ascertain from the file who participated in the formulation of the treatment plan; however, it appeared that it was formulated by the social worker and signed by the social worker and the parents.

In Case A no resources were offered to the mother to keep her safe once the child had been removed, again indicating a purely child-centred focus. It is worth noting, though, that not providing the mother with resources once the children are removed is contrary to the principle of family preservation, as the children will not be returned to the mother's care until she can provide a safe environment. In Case B the mother was offered shelter once the children had been removed, but she refused the offer. 
The abusers were included in the intervention in both cases. In Case A the perpetrators were interviewed during the fact-finding phase and then they were referred out for counselling. No other services were offered. In Case B the abusers were referred to SANCA and individual counselling was offered. Referrals were made in both cases to various service providers and professionals. It is noteworthy that intervention with the abusers occurred on a micro level, with a focus on counselling. There is a distinct absence of mezzo- and macro-level interventions in practice.

\section{Evaluation and follow up of service}

In Case A there was no evidence on file of an evaluation. Evaluation is closely linked to assessment; without an evaluation one cannot establish whether the intervention has been successful in decreasing the risk to a point where both the mother and child are safe.

In Case B there were periodic progress reports and notes from the supervisor; however, the evaluation was done exclusively by the social worker and her supervisor, and the client system was not included in the process.

There were no follow-up services provided in Case A as the file was transferred to the agency supervising the foster care placement once the Children's Court enquiry had been finalised. This does not necessarily mean that there was no follow up in the case; rather the follow up occurred in a different department of the organisation. Although the recording on Case B is difficult to follow, it does seem that there were regular follow ups, either face to face or telephonically, between the client system and the social worker.

\section{Theoretical framework}

In the study of studying human behaviour, theories are used to attain two important goals: explanation and prediction (Robbins et al., 1998). This is important in the study of the cooccurrence of woman and child abuse, as the theoretical orientation of both the social worker and the organisation will in turn influence the practitioner's understanding of the phenomenon as well as the choice of intervention. For example, studies have found that social workers with certain theoretical orientations largely ignored clues about the dangerous and sometimes fatal nature of a domestic violence case (Saunders \& Anderson, 2000). In both Cases A and B there is a problem-focused approach in both the assessment of the situation as well as the formulation of the treatment goals. In Case A there is a particular focus on the medical model as the case was referred by the hospital and the main focus was on the injuries of the child. The medical model focuses on pathology and diagnosis as well as on remediation and individual clinical practice; the result is that there is little emphasis on the development of individual, family and community strengths and a greater emphasis on remediation and individual clinical practices (Patel, 2005).

The problem-focused approach in both cases resulted in the families being seen in terms of their problems and weaknesses rather than in terms of their strengths. The problem-focused approach also limited the understanding of other social issues or contributing factors and their impact on the family (Cameron, Freymond, Cornfield \& Palmer, 2001). This in turn limited the interventions to dealing solely with the symptoms (e.g. alcohol abuse) rather than the causes or contributing factors. The problem-focused approach also defines the clients in terms of their presenting problems, which excludes them from contributing to their treatment plan and change process (Patel, 2005). In Case A the intervention focused entirely on the child, which meant that although there was a suspicion of woman abuse, this was never explored. The focus on 
problems rather than strengths results in a reactive rather than a preventative intervention response (Patel, 2005).

Although not specifically stated as strengths, positive factors about the parents were also identified in both cases. Despite the abuse in Case A, the parents maintained regular contact with the child. This strength was promoted by the social worker, who encouraged parental contact as well as parental involvement in the child's upbringing. In Case B the family continually sought help from the organisation concerned in times of crisis; however, there is no evidence on the file as to how family strengths were identified or developed. The strengthsbased approach to woman and child abuse is strongly advocated by Fleck-Henderson (2000) as it may balance the focus on risk in child protection. Strengths-based assessments enhance the individualisation of clients. The focus is on the uniqueness of each client in terms of their interests and abilities, and how they have managed their problem situation. Pivotal to the strengths perspective is the belief that clients are inherently trustworthy. The recognition of client strengths as well as the development of internal and external resources is therefore crucial (Saleebey, 2002).

The social work skills in both cases that were evident on the case files were interviewing skills, referral skills, risk assessment and report writing skills. It was difficult to ascertain what values (personal or professional) influenced the intervention; however, no judgmental or derogatory terms were used in the file. It was noted in Case A that once the alleged perpetrator had been verbally aggressive towards the social worker, she withdrew contact and there was expressed anxiety regarding any further interventions involving the father. Research confirms the reluctance of social workers to include abusers in the intervention process for those very reasons (Mullender, 1996).

\section{LESSONS FROM PRACTICE}

A number of valuable lessons can be gleaned from the case studies in terms of practice with specific reference to intervention and assessment.

The first lesson is the importance of comprehensive assessment procedures. The assumption that the co-occurrence of woman and child abuse in the same family system occurs was confirmed in that both forms of abuse were evident in both of the case studies. However, the case studies established that the possibility that more than one form of abuse may be occurring on the same case is not explored by practitioners. Given that agency mandates stipulate service provision to either women or children exclusively, the co-occurrence of woman and child abuse is not recognized or recorded as such. There is a lack of guidelines for assessment of woman and child abuse, and social workers do not assess for the abuse of other family members unless it is their mandate to do so. Even when it is apparent that other members of the family are at risk, this does not appear to be assessed or addressed. A gender-sensitive approach is therefore crucial if issues particular to women are to be recognised even in settings where the primary client may not be the mother. In addition, standardised screening procedures are therefore necessary to ensure early detection and identification of the co-occurrence of woman and child abuse (Stephens, 1999).

Assessment appears to occur concurrently with intervention, which is appropriate in crisis intervention. However, if assessment processes are unclear, the formulation of successful intervention plans and interventions may be hindered. In order to decrease risk and ensure appropriate and effective intervention plans, early identification of woman abuse in child abuse cases needs to occur and vice versa (Echlin \& Osthoff, 2000; Eisikovits \& Buchbinder, 2000). 
A history of childhood abuse in the parents is rarely investigated and this is shown to be a major risk factor for future abusive parenting styles (Eisikovits \& Buchbinder, 2000).

The second lesson is the importance of moving away from exclusively micro-level and crisis intervention strategies toward intervention on all levels of practice.

The study showed a tendency to focus on micro-level interventions, particularly individual counselling. Although micro-level interventions are both important and relevant, it is essential that intervention should occur on all levels if family violence is to be adequately addressed. Internationally and locally researchers are emphasising the importance of moving away from seeing family violence as merely a private, individual issue that requires micro-level intervention to seeing it as a public problem that requires micro-, mezzo- and macro-level interventions (Dangor, 1999; Owens-Manley, 1999). The case study also highlights the lack of preventative interventions. These are needed not only to provide services to at-risk population groups, but also to provide a platform for clients to engage with social workers in a nonthreatening environment. Research suggests that the best way of moving away from the split between services to abused women and those provided to abused children is to deal with the phenomenon together at a preventative level (Magen et al., 2000). Unlike protective services, preventative services do not have the stigma of either child maltreatment or battered women. When working preventatively, one can address a blanket at-risk population in a way that would benefit both women and children (Magen et al., 2000). Such services could take the form of mother-infant clinics, medical services specifically geared towards women, and community resource centres.

There appears to be an emphasis on short-term and crisis responses, with little attention paid to medium- to long-term interventions. This calls into question the sustainability of services. Incorrect service provision or services that do not attend to the more long-term needs of the client may result in clients remaining service receivers and may prevent them from becoming self-sufficient (Owens-Manley, 1999).

The third lesson highlights the significance of integrating different theoretical approaches. The case study analysis demonstrated a tendency towards using the problem-solving approach without integrating any other theoretical frameworks. The problem-solving approach can be useful in child welfare and women's advocacy settings. However, when used exclusively, there is an inclination to focus purely on the problems and not on the strengths. Thought should therefore be given to adopting other theoretical approaches such as the generalist practice approach (Kirst-Ashman \& Hull, 2002), so that the useful aspects of different theoretical frameworks can be combined to meet the needs of all client groups.

The forth lesson focuses on the complex nature of woman and child abuse and the likelihood that they may occur along with many other social issues. This emphasizes the importance of collaboration between different organisations. These issues cannot be addressed by a single organisation and joint case conferences as well as consultations are essential to create a platform for more comprehensive assessments and intervention plans. Not only should collaboration take place between different service providers but, most essentially, collaboration is needed between child protection/welfare workers and those working in women's advocacy organisations to overcome the bifurcation of services and to meet the needs of all family members (Fleck-Henderson, 2000). 


\section{CONCLUSION}

This article has demonstrated that cases where woman and child abuse are present in the same family system do exist and the international literature suggests that this is a phenomenon that is unrecognised and on the increase. The importance of agency mandates that stipulate the assessment of, and intervention with, the entire family system rather than one member exclusively, as well as comprehensive assessment procedures, is stressed. The article also demonstrates through the cases studies that the co-occurrence of woman and child abuse is a complex phenomenon that involves numerous social issues and requires intervention on many levels. Following this, one can conclude that a social phenomenon of such a complex nature would require the fusion of different theoretical frameworks that would allow for the needs of all member of the family to be adequately addressed. Collaboration between different social service organisations - particularly those that serve women and those that serve children - is of vital importance. In order to incorporate the aforementioned factors in addressing the cooccurrence of woman and child abuse, the author proposes that a generalist practice framework underpinned by the values of empowerment and gender sensitivity be adopted.

Finally, the case studies highlighted the seriousness of this phenomenon as well as a need for further research, on both a quantitative and qualitative level, on the co-occurrence of woman and child abuse in the same family system in South Africa.

\section{REFERENCES}

BEEMAN, S.K. \& EDLESON, J.L. 2000. Collaborating on family safety: challenges for children's and women's advocates. In: GEFFNER, R.A., JAFFE, P.G. \& SUDERMANN, M. (eds) Children exposed to domestic violence: current issues in research, intervention, prevention and policy development. New York: The Haworth Maltreatment and Trauma Press.

BRIEDLAND, D., COSTIN, L.B. \& ATHERTON, C.R. 1975. Contemporary social work: an introduction to social work and social welfare. United States of America: McGraw Hill Book Company.

CAMERON, C., FREYMOND, N., CORNFIELD, D. \& PALMER, S. 2001. Positive systems for children and family welfare: options for expanding the Anglo-American child protection paradigm. Draft paper. Partnerships for Children and Families Project. Wilfred Laurier University, Canada, October 2001.

CHAMBERLAIN, L. 2001. Domestic violence and child abuse: ten lessons learned in rural Alaska. Policy and Practice of Public Human Services, 59(1):32-39.

DANGOR, Z. 1999. Life after abuse: an exploration of women's strategies for overcoming abuse. Johannesburg: Rand Afrikaans University. (Unpublished DLitt et Phil Psychology Thesis)

DE VOS, A.S. (ed) 2001. Research at grass roots: a primer for the caring professions. Pretoria: Van Schaik Publishers.

DOMINELLI, L. 2002. Feminist social work theory and practice. Great Britain: Palgrave.

ECHLIN, C. \& OSTHOFF, B. 2000. Child protection workers and battered women's advocates working together to end violence against women and children. In: GEFFNER, R.A., JAFFE, P.G. \& SUDERMANN, M. (eds) Children exposed to domestic violence: current issues in 
research, intervention, prevention and policy development. New York: The Haworth Maltreatment and Trauma Press.

EDLESON, J.A. 2001. Studying the co-occurrence of child maltreatment and domestic violence in families. In: GRAHAM-BERMAN, S.A. \& EDLESON, J.L. (eds) Domestic violence in the lives of children: the future of research, intervention, and social policy. Washington DC: American Psychological Association.

EISIKOVITS, Z. \& BUCHBINDER, E. 2000. Locked in a violent embrace: understanding and intervening in domestic violence. United States of America: Sage Publications.

FIEGGEN, A.G., WEIMANN, M., BROWN, C., VAN AS, A.B., SWINGLER, G.H. \& PETER, J.C. 2004. Inhuman Shields-children caught in the crossfire of domestic violence. South African Medical Journal, 94(4):293-296.

FLECK-HENDERSON, A. 2000. Domestic violence in the child protection system: seeing double. Children and Youth Services Review, 22(5):333-354.

HAMPTON, R.L. \& WASHINGTON CONER-EDWARDS, A.F. 1993. Physical and sexual violence in marriage. In: HAMPTON, R.L., GULLOTTA, T.P., ADAMS, G.R., POTTER, E.H. \& WEISSBERG, R.P. (eds) Family violence: prevention and treatment. United States of America: Sage Publications.

HANSON, S. 2008. A generalist practice framework to address the co-occurrence of woman and child abuse in South Africa. Johannesburg: University of Johannesburg. (Unpublished DLitt et Phil Social Sciences Thesis)

HANSON, S. \& PATEL, L. 2009. Beyond the practice divide in service delivery for abused women and children. The Social Work Practitioner-Researcher, 21(2):166-182.

HANSON, S. \& PATEL, L. 2010. Linking the circles of violence: woman and child abuse in the same family systems in South Africa. Practice: Social Work in Action, 22(1):33-44.

HERRERA, V.M. \& McCLOSKEY, L.A. 2001. Gender differences in the risk for delinquency among youth exposed to family violence. Child Abuse and Neglect, 25(8):1037-1051.

JACKSON, R.L. 2001. The Clubhouse Model: empowering applications of theory to generalist practice. United States of America: Brooks/Cole Publishing.

JACOBS, T. \& JEWKES, R. 2002. Vezimfilho: a model for health sector response to gender violence in South Africa. International Journal of Gynaecology and Obstetrics, April:1-8.

JOHNSON, L. 1992. Social work practice: a generalist approach. Boston: Allyn \& Bacon.

KIM, J. \& MOTSEI, M. 2002. Women enjoy punishment: attitudes and experiences of genderbased violence among PHC nurses in rural South Africa. Social Science and Medicine. 54(8):1243-1254.

KIRST-ASHMAN, K.K. \& HULL, G.H. 2002. Understanding generalist practice. United States of America: Brooks/Cole Publishing.

MAGEN, R.H., CONROY, K. \& DEL TUFO, A. 2000. Domestic violence in child welfare preventative services: results from an Intake Screening Questionnaire. Children and Youth Services Review, 22 (3/4):251-274.

MARLOW, C.R. 2005. Research methods for generalist social work $\left(4^{\text {th }} \mathrm{ed}\right)$. United States of America: Thomson, Brooks/Cole. 
MATTAINI, M.A., LOWERY, C.T. \& MEYER, C.H. (eds) 2002. Foundations of social work practice: a graduate text ( $3^{\text {rd }}$ ed). Washington DC.: NASW Press.

McKAY, M. 1994. The link between domestic violence and child abuse: assessment and treatment considerations. Child Welfare League of America, 73(1):60-65.

MILLS, L.G., FRIEND, C., CONROY, K., FLECK-HENDERSON, A., KRUG, S., MAGEN, R.H., THOMAS, R.L. \& TRUDEAU, J.H. 2000. Child protection and domestic violence: training, practice and policy issues. Children and Youth Services Review, 22(5):315-332.

MULLENDER, A. 1996. Rethinking domestic violence: the social work and probation response. London: Routledge.

MULLENDER, A. 2001. Meeting the needs of children. In: TAYLOR-BROWN, J. (ed) What works in domestic violence? A comprehensive guide for professionals. England: Whiting and Birch Ltd.

MUllendER, A., HAGUE, G., IMAM, U., KELLY, L., MALOS, E. \& REGANN, L. 2002. Children's perspectives on domestic violence. Great Britain: Sage Publications.

OWENS-MANLEY, J. 1999. Battered women and their children: a public police response. Journal of Women and Social Work, 14(4):439-460.

PARK, Y.J. \& KAHN, F. 2000. Helping the hidden victims: sheltering the children of abused women. In: PARK, Y.J., FEDLER, J. \& DANGOR, Z. 2000. Reclaiming women's spaces: new perspectives on violence against women and sheltering in South Africa. Johannesburg: NISAA Institute for Women's Development.

PATEL, L. 2005. Social welfare and social development in South Africa. South Africa: Oxford University Press.

ROBBINS, S.P., CHATTERJEE, P. \& CANDA, E.R. 1998. Contemporary human behaviour theory: a critical perspective for social work. Boston: Allen and Bacon.

ROSSMAN, R.B.B., HUGHES, H.M. \& ROSENBERG, M.S. 2000. Children and interparental violence: the impact of exposure. United States of America: Brunner/Mazel.

SALEEBEY, D. (ed) 2002. The strengths perspective in social work practice $\left(3^{\text {rd }}\right.$ ed). New York: Longman.

SALZINGER, S., FELDMAN, R., STOCKHAMMER, T. \& HOOD, J. 2002. An ecological framework for understanding risk for exposure to community violence and the effects of exposure on children and adolescents. Aggressive and Violent Behaviour. In Press Uncorrected Available online January 2002.

SAPPINGTON, A.A. 2000. Childhood abuse as a possible locus for early intervention into problems of violence and psychopathology. Aggression and Violent Behaviour, 5(3):255266.

SAUNDERS, D.G. \& ANDERSON, D. 2000. Evaluation of a domestic violence training for child protection workers and supervisors: initial results. Children and Youth Services Review, 22(5):373-395.

SCHEWE, P.A. 2002. Preventing violence in relationships: interventions across the lifespan. Washington: American Psychological Association. 
SOUTH AFRICAN POLICE SERVICES. 2008. Crime Information Analysis Centre: neglect and ill-treatment of children in the RSA for the period April-March 2001/2002 to 2007/2008. [Online] Available: www.saps.org.za [Accessed: August 2008].

STEPHENS, D.L. 1999. Battered women's views of their children. Journal of Interpersonal Violence, 14(7):731-745.

WHITNEY, P. \& DAVIS, L. 1999. Child abuse and domestic violence in Massachusetts: can practice be integrated in a public child welfare setting? Child Maltreatment. 4(2):158-167.

Dr Sheri Hanson, Post-doctoral Fellow at the Centre for Social Development in Africa, University of Johannesburg, South Africa. 